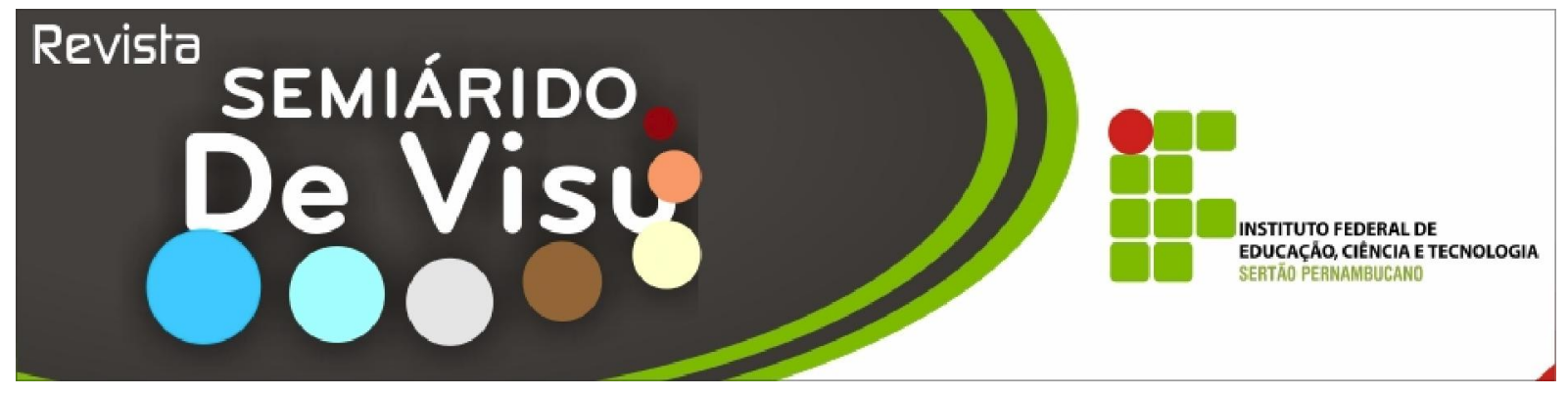

\title{
Avaliação das condições higiênico-sanitária no preparo de sushi e sashimi de um estabelecimento comercial
}

\author{
Thayse Wilma Nogueira de Oliveira ${ }^{1}$; Luciana Façanha Marques ${ }^{2}$ \\ 1 Tecnóloga em Alimentos Faculdade de Tecnologia CENTEC - FATEC CARIRI \\ 2 Professora do IF Sertão Pernambucano - Campus Salgueiro-PE BR 232 km 509 Zona Rural (87) 3421-0050 \\ luciana.marques@ifsertao-pe.edu.br
}

\begin{abstract}
RESUMO: Este trabalho teve como objetivo avaliar as condições higiênico-sanitárias na preparação e comercialização do Sushi e Sashimi de um estabelecimento comercial. O estudo foi realizado no setor de preparação de um supermercado localizado no Cariri Cearense onde foram realizados o teste de $S w a b$, análises microbiológicas dos produtos prontos para o consumo e aplicação de uma lista de verificação (check-list) sobre as condições do setor. No teste de Swab dos equipamentos, utensílios e mãos dos manipuladores os resultados indicaram contaminação por bactérias mesófilas acima do permitido em sete das oito amostras avaliadas, indicando a falta do processo de higienização nos processos do setor. Nas análises microbiológicas do sushi de salmão, sushi de camarão, sashimi e salada de camarão, somente este último apresentou-se imprópria para consumo devido a contagem de Staphylococcus spp., acima do permitido pela ANVISA. A lista de verificação do setor indicou 78,57\% de conformidades, indicando o não seguimento de alguns pontos importantes das Boas Práticas de Fabricação, importantes para garantir a produção de alimentos mais seguros.
\end{abstract}

Palavras-chave: Sushi, sashimi, contaminação, peixe, higiene.

\section{Evaluation of the hygienic and sanitary conditions in the preparation of sushi and sashimi a commercial establishment}

\begin{abstract}
This study aimed to evaluate the sanitary conditions in the preparation and sale of Sushi and Sashimi a commercial establishment. The study was carried out at the preparation of a supermarket located in Cariri Cearense, being performed a swab test, microbiological analysis of products ready for consumption and use of a checklist on industry conditions. Swab the test equipment, utensils and hands of food handlers, the results indicated contamination by mesophilic bacteria above that allowed in seven of eight samples, indicating the lack of the process of cleaning processes in the industry. Microbiological analysis of salmon sushi, shrimp sushi, sashimi and shrimp salad, only the latter presented himself unfit for use due to Staphylococcus spp., Above that allowed by ANVISA. The checklist indicated $78.57 \%$ of industry compliance, indicating failure to follow a few important points of the Good Manufacturing Practices, important to ensure the production of safer food.
\end{abstract}

Keywords: Sushi, sashimi, contamination, fish, hygiene. 
Thayse Wilma Nogueira de Oliveira \& Luciana Façanha Marques

\section{Introdução}

$\mathrm{O}$ s supermercados incluem todos os estabelecimentos do varejo alimentar com um sistema tecnologicamente sofisticado para estocagem e preparação de alimentos para a venda em que muitos produtos são vendidos préempacotados. A loja varejista é o último elo numa cadeia comercial entre o produtor e o consumidor final dos alimentos, representando um ponto extremo, onde o controle pode ser aplicado ao manuseio e armazenamento (GIOVA, 1997).

O controle de qualidade em um supermercado proporcionará diminuição nos riscos de infecções alimentares, maior segurança nos produtos oferecidos à venda, redução nas perdas, além de prestigio para a empresa. Haverá controle e inspeção diários visando melhoria dos processos, recebimento de mercadorias, armazenamento correto, higienização e manipulação (RODRIGUES, 2008).

No Brasil, o consumo de pescado in natura cresce a cada ano, sendo o peixe cru (sushi e sashimi) um produto cada vez mais consumido em estabelecimentos especializados. Nesse contexto, a culinária japonesa pode ser destacada como uma das principais responsáveis pelo maior consumo de pescado, que é um alimento completo, capaz de proporcionar ao organismo todas as substâncias necessárias e não sintetizáveis, tratando-se de um produto de excelente composição de aminoácidos, vitaminas e sais minerais, além de ser rico em ácidos graxos (FILHO, 2007).

O sushi é constituído à base de arroz temperado com molho de vinagre, açúcar e sal, e combinados com peixe ou frutos do mar, ou ainda vegetais, frutas ou ovo, envolvidos em uma fina camada de algas marinhas (CHAYB, 2010). O sashimi consiste em fatias de peixe ou pescado cru, de várias espécies, servidas com molho de soja e pasta de raiz forte, denominada wassabi (SILVA, 2007).

$\mathrm{Na}$ produção destes produtos deve-se trabalhar com peixes de ótima qualidade e de procedência conhecida; além disso, deve-se ter cuidado todo especial com a manipulação do produto para que não se contamine o pescado uma vez que o mesmo é consumido cru (LIMA, 2001). Os principais pescados utilizados na preparação do sushi são o salmão, atum, polvo, camarão, linguado, lula, carapau, cavalinha e etc.. Além destes podem ser utilizados frutas e vegetais, omeletes, kani, entre outros, variando o sabor e aparência do produto. Existem vários tipos de sushi e dependendo recheio este recebe um nome diferente, onde os principais são: sakemaki (com recheio de salmão), tekkamaki (enrolado com recheio de atum), uramaki (enrolados com alga para dentro), niguiri (bolinho de arroz com peixe em cima e pode vir com uma tirinha de nori - alga), temaki (sushi em forma de cone), hot sushi (Sushi frito). Todos saboreados com o Wassabi - Raiz forte (rábano verde) e/ou o molho shoyo - molho de soja (CHAYB, 2010).

A biota microbiana do pescado é reflexo da água onde vive, ou seja, da natureza do habitat e variação da temperatura. A microbiota normal é geralmente encontrada em três regiões: no muco interno, nas guelras e no intestino. Os tecidos internos de um peixe saudável são estéreis, sendo que a contaminação nestes é indício de manipulação sem os devidos cuidados. Baixos índices de contaminantes encontrados nas guelras e na pele são comumente associados às águas limpas e frias, e os índices mais elevados às água tropicais, subtropicais e áreas poluídas (MARTINS, 2006).

Com a crescente popularização do consumo de peixe cru (sushi e sashimi) aumenta a preocupação com a qualidade higiênico-sanitária dos pescados e de suas preparações, uma vez que pescados crus são veículos de agentes causadores de infecções e intoxicações alimentares.

Durante a preparação de vários pratos a partir de pescado, agentes patogênicos presentes no material cru podem ser eliminados ou sobreviverem e estarem presentes no produto final. Quando o produto é armazenado sobre refrigeração, a preocupação concentra-se na sobrevivência de multiplicação de microrganismos psicotróficos. O tratamento com calor, como cocção, é eficiente na destruição de alguns patógenos, quando 
realizado sob temperatura e tempo adequados. Porém, o hábito de consumir pescados crus torna a prevenção de DTA's (Doenças Transmitidas por Alimentos) difícil ou até impossível (MARTINS, 2006).

Na preparação de iguarias como Sushi e Sashimi, preparadas manualmente, além da contaminação do pescado, o contato direto do alimento com as mãos pode levar ao aumento da incidência de patógenos como Staphylococcus aureus e coliformes termotolerantes. Segundo Silva et al. (2007), preparações muito manipuladas são consideradas de alto risco, especialmente quando elaboradas por pessoas que não possuem treinamento adequado. Além disso, preparações a base de pescado cru oferecem risco ainda maior à saúde pelo fato de não serem submetidos a tratamentos bactericidas como cocção.

Este trabalho tem como objetivo avaliar as condições higiênico-sanitárias na preparação e comercialização do Sushi e Sashimi de um estabelecimento comercial.

\section{Material e métodos}

O presente estudo foi realizado no setor de Sushi e Sashimi de um supermercado localizado no Cariri Cearense. Foram realizados os teste de $S w a b$, análises microbiológicas dos produtos prontos para o consumo e aplicado uma lista de verificação (check-list) sobre as condições do setor.

\section{- Teste de $S w a b$ :}

O teste de swab foi aplicado aos equipamentos, utensílios e manipuladores do estabelecimento em pesquisa. As amostras foram coletadas no dia 11 de abril de 2011 utilizando-se uma "zaragatoa" que foi previamente esterilizada, e passadas, uma a uma, nas superfícies das: cubas de arroz, tábua de corte, facas, barca de exposição dos produtos, geladeira, balcão térmico, e de dois manipuladores em meio à preparação dos produtos. Terminado esta etapa as amostras foram encaminhadas até o Laboratório de
Microbiologia de Alimentos da Faculdade de Tecnologia CENTEC - FATEC CARIRI onde foram realizadas as análises para pesquisa de bactérias mesófilas.

No laboratório foram preparadas as diluições $10^{-1}, 10^{-2}$ e $10^{-3}$ a partir do tubo contendo a zaragatoa e distribuído $1 \mathrm{ml}$ no centro das placas Petri estéreis, em seguida, adicionando de cerca de $15 \mathrm{ml}$ de Agar Padrão para contagem total fundido e resfriado a $45^{\circ} \pm$ $1^{\circ} \mathrm{C}$ em superfície plana, submetendo a placa a duas séries alternadas de cinco movimentos rotativos, deixando solidificar. Em seguidas as placas foram incubadas invertidas a $37^{\circ} \pm 1^{\circ} \mathrm{C}$ por 48 horas.

\section{- Análises microbiológicas dos produtos acabados:}

As amostras foram obtidas no estabelecimento em estudo, como são oferecidas aos consumidores, prontas para o consumo. Foram colhidas quatro amostras uma de cada variedade que encontrava-se exposta, que são: Sushi de salmão, sushi de camarão, salada de camarão e sashimi. Estas foram acondicionadas em recipientes térmicos para manter sua temperatura de exposição e levadas ao Laboratório de Microbiologia de Alimentos da FATEC-CARIRI onde foram submetidas às análises para detecção de Coliformes a $45^{\circ} \mathrm{C}$, Staphylococcus spp e pesquisa de Salmonella spp, segundo métodos descritos pela Food and Drug Administration (FDA).

\section{- Aplicação de Check-list}

No mês de maio foi aplicada uma lista de verificação (check-list) com o objetivo de avaliar quais as conformidades e não conformidades do setor em estudo.

A lista de verificação foi composta por 28 perguntas, organizadas em uma única tabela contendo todos os espaços para as respostas de cada aplicação. A nota foi dada através da somatória de todas as respostas positivas, em relação a quantidade de perguntas e multiplicadas por 100 para que a reposta seja em porcentagem de conformidades do setor de sushi e sashimi. De acordo com a resposta, o 
setor pode ser classificado em Ótimo (76 a $100 \%$ ), Bom (51 a $75 \%$ ) ou Regular (0 a 50\%).

\section{Resultados e discussão}

\section{Swab}

Foram obtidas as seguintes contagens de bactérias mesófilas nas análises de swab dos equipamentos, utensílios e manipuladores (Tabela 1).

Tabela 1: Resultados do swab nos equipamentos, utensílios e manipuladores.

\begin{tabular}{ccc}
\hline Amostra & Resultado da Análise (UFC/g) & Permitido pela Legislação \\
\hline Cubas de Arroz & $5,1 \times 10^{2}$ & $<10$ \\
Tábua de Corte & $2,8 \times 10^{2}$ & $<10$ \\
Facas & Incontável & $<10$ \\
Barcas & $6,0 \times 10^{2}$ & $<10$ \\
Geladeira & $4,15 \times 10^{5}$ & $<10$ \\
Balcão Térmico & $6,25 \times 10^{2}$ & $<10$ \\
Manipulador 01 & $<10$ & $<10$ \\
Manipulador 02 & $6,55 \times 10^{3}$ & $<10$ \\
\hline
\end{tabular}

$\mathrm{UFC} / \mathrm{g}=$ Unidades Formadoras de Colônias por grama

Como mostrado na tabela acima somente a mão de um dos manipuladores apresentou uma contagem de bactérias mesófilas dentro do permitido pela legislação. As demais amostras encontravam-se bem acima do permitido, tendo a faca apresentado valor incontável.

Os equipamentos e utensílios em geral devem conter, no máximo, 50 bactérias $/ \mathrm{cm}^{2}$ e ausência de microrganismos potencialmente patogênicos ou indicadores de contaminação fecal. Estes critérios, segundo ABERC, 2000 devem ser atingidos pela lavagem com água e sabão com ou sem desinfecção final. Diante do resultado encontrado podemos comprovar que os utensílios não foram higienizados adequadamente ou mesmo nem passaram por este processo. Todo objeto que entre em contato direto com o alimento ou que faça parte do processo de produção devem passar pelo processo de higienização, que consiste na limpeza com detergente e em seguida a desinfecção, para a eliminação de microorganismos que possam contaminar os próximos alimentos a serem processados. Este procedimento é essencial para garantir a inocuidade do produto final e tendo em vista que o alimento será consumido cru, alguns cuidados devem ser redobrados, pois o risco de contaminação e a ocorrência de um surto de infecção alimentar são altos.
A geladeira e o balcão térmico não entram em contato direto com o produto avaliado, mas podem vir a se tornar veiculo de contaminação aos utensílios e as mãos dos manipuladores. Desta forma é indispensável a higienização destes equipamentos frequentemente.

VANZO \& AZEVEDO, 2003 realizaram um estudo do qual participaram 67 manipuladores de alimentos, no grupo etário variando de 20 a 59 anos, de ambos os sexos, $(28,4 \%$ homens $)$ e $(76,6 \%$ mulheres $)$, totalizando 268 amostras. Constataram que $41,8 \%$ dos manipuladores de alimentos albergavam Estafilococos nas mãos, 35,7\% na boca e $25 \%$ nas fossas nasais. De todas as amostras analisadas nesse trabalho as mãos dos manipuladores também foi a que apresentou um maior número de bactérias mesófilas. Isto indica a falta de higiene pessoal do manipulador, e isto não deveria ocorrer, pois suas mãos estão em contato com o alimento produzido, o que acarreta na contaminação do mesmo.

As bactérias mesófilas são aquelas que apresentam temperatura ótima de multiplicação entre $25^{\circ}$ e $40^{\circ} \mathrm{C}$, mínima entre $5^{\circ}$ e $25^{\circ} \mathrm{C}$, e máxima entre $40^{\circ}$ e $50^{\circ} \mathrm{C}$. Estes correspondem à grande maioria daqueles de importância em alimentos, inclusive a maior parte dos patógenos de interesse. A presença de bactérias 
mesófilas em grande número indica matériaprima excessivamente contaminada; limpeza e desinfecção de superfícies inadequadas; higiene insuficiente na produção ou conservação dos alimentos; condições inadequadas de tempo/temperatura durante a produção ou a conservação dos alimentos, ou uma combinação destas circunstâncias (FRANCO e LANDGRAF, 1996; SIQUEIRA, 1995).

\section{Analises Microbiológicas dos produtos prontos}

Foram obtidos os seguintes resultados para as análises microbiológicas do Sushi, Sashimi e Salada de camarão conforme a Tabela 2 abaixo:

Tabela 2: Resultados das análises microbiológicas do sushi, sashimi e salada de camarão

\begin{tabular}{cccccc}
\hline \multirow{2}{*}{ Análises } & \multicolumn{4}{c}{ Amostras } & Limite permitido \\
\cline { 2 - 5 } & $\begin{array}{c}\text { Sushi de } \\
\text { Salmão (A) }\end{array}$ & $\begin{array}{c}\text { Sushi de } \\
\text { Camarão (B) }\end{array}$ & $\begin{array}{c}\text { Salada de } \\
\text { camarão (C) }\end{array}$ & $\begin{array}{c}\text { Sashimi } \\
\text { (D) }\end{array}$ & $\begin{array}{c}\text { (ANVISAção } \\
\text { (ANVISA }\end{array}$ \\
\hline Staphylococcus & $<10$ & $<10$ & $1,05 \times 10^{4}$ & $<10$ & $5 \times 10^{2} \mathrm{NMP} / \mathrm{g}$ \\
Salmonella & Ausente & Ausente & Ausente & Ausente & Ausente \\
Coliformes Fecais & $3 \mathrm{NMP} / \mathrm{g}$ & $<3 \mathrm{NMP} / \mathrm{g}$ & $11 \mathrm{NMP} / \mathrm{g}$ & $11 \mathrm{NMP} / \mathrm{g}$ & $10^{2} \mathrm{NMP} / \mathrm{g}$ \\
\hline
\end{tabular}

$\mathrm{NMP} / \mathrm{g}=$ Numero Mais Provável por grama da amostra.

Estes resultados demonstram que as amostras $\mathrm{A}, \mathrm{B}$ e $\mathrm{D}$ encontram-se dentro dos padrões estabelecidos pela Agencia Nacional de Vigilância Sanitária (ANVISA) através da RDC $n^{\circ} 12$ de 2001, confirmando que estão aptas ao consumo. No entanto a amostra C referente a salada de camarão, apresentou um alto índice de Staphylococcus, encontrando-se acima do padrão e tornando-se um risco a saúde do consumidor.

Este resultado negativo na amostra de salada demonstra que pode ter ocorrido contaminação humana. Segundo Martins (2006), as bactérias do gênero Staphylococcus são habitantes usuais da pele, das membranas mucosas, do trato respiratório superior e do intestino do homem e animais. A partir destes, as bactérias podem atingir o ar, água, solo, leite, esgoto e qualquer superfície ou objeto que tenha entrado em contato com infectado. Dessa forma, todos os alimentos ficam sujeitos a contaminação; e se os mesmo apresentarem boas condições para o crescimento do patógeno, o alimento será uma fonte de intoxicação.

Além da manipulação inadequada, a matéria-prima pode ter uma boa parte da culpa por este alto índice de bactérias. Os pescados são facilmente contaminados por microrganismos que vivem no ambiente aquático, que se não houver cuidados especiais podem se desenvolver e causar a contaminação do alimento processado. Outro motivo seria a realização inadequada da desinfecção das cebolinhas, produto hortícola utilizado no alimento em questão.

A ausência de Salmonela e a contagem de Coliformes Fecais dentro dos padrões estabelecidos em todas as amostras indicam que não houve contaminação fecal nos alimentos em estudo. Estes microrganismos são patógenos ou indicadores de poluição fecal, raramente encontrado nos pescados recémcapturados. Após captura, a microbiota inicial é alterada pelo transporte, manipulação, contato com gelo contaminado, superfície e equipamentos, estocagem e comercialização (CARDOSO et al., 2003).

A contaminação pré-captura com patógenos de reservatórios animal/humano pode oferecer risco, pois em alguns casos uma dose infectante baixa é suficiente para provocar uma doença. A cocção de alimentos com esta contaminação elimina o risco destes patógenos, sendo que a principal preocupação com segurança se relaciona ao consumo destes crus, como nos casos de Sushi e Sashimi (MARTINS, 2006). 
Thayse Wilma Nogueira de Oliveira \& Luciana Façanha Marques

\section{Aplicação de Check-list:}

O setor apresentou uma porcentagem de conformidades de $78,57 \%$ na lista de verificação aplicada no mês de maio, ou seja, das 28 conformidades avaliadas foram encontradas apenas 6 pontos não conformes. $\mathrm{O}$ check-list nos permite fazer uma avaliação preliminar das condições higiênico sanitárias de um estabelecimento produtor de alimentos. Esta avaliação inicial permite levantar itens não conformes e, a partir dos dados coletados, traçar ações corretivas para adequação dos requisitos buscando eliminar ou reduzir riscos de contaminação, que possam comprometer a qualidade do produto final (SEIXAS, 2008).

Um dos pontos negativos verificados foi à ausência de um lavatório exclusivo para higiene das mãos. Durante a aplicação pode-se observar que o lavatório do setor é utilizado para lavar utensílios entre outros fins. Este, mesmo não sendo exclusivamente para higiene das mãos, continha sabonete, papel toalha e um informativo com as etapas de higiene das mãos. As mãos devem ser lavadas toda vez que o manipulador mudar de atividade durante $o$ período de trabalho, em especial quando deixar de manipular alimentos crus, e for preparar alimentos cozidos (HAZELWOOD, 1998).

Segundo o Regulamento Técnico sobre "Condições Higiênico-Sanitárias e de Boas Práticas de Fabricação para Estabelecimentos Produtores/Industrializadores de Alimentos (1997), todas as lâmpadas do local onde se manipulam alimentos devem ser protegidas, para evitar uma possível contaminação caso ocorra a quebra das mesmas. No setor esta regra não é obedecida, sendo todas as lâmpadas sem proteção.

Dois dos equipamentos essenciais no setor, fritadeira e panela elétrica encontravamse com sujidades em sua parte externa, mostrando-se que não foram higienizadas adequadamente por fora. Alguns produtos fracionados armazenados na geladeira não estavam identificados com nome, data de embalagem e data de validade, desta forma não é garantida que aquele produto esta apta a sua utilização, pois não há como comprovar se esta vencida ou não.

As bancadas não estavam limpas durante a verificação e alguns utensílios se encontravam em mal estado de conservação, com arranhões que podem vir a armazenar sujidades e microrganismos, que poderão contaminar os produtos prontos. A higienização inadequada de superfícies, equipamentos e utensílios aumentam a probabilidade de contaminação, que leva a uma redução na vida de prateleira e aumenta a possibilidade de presença de microrganismos patogênicos. Este é um fator crítico na segurança alimentar e, portanto, é necessário averiguar a eficácia dos procedimentos de higienização (PIRES, 2005).

Quanto aos manipuladores, todos se encontravam bem apresentados, com uniformes limpos e íntegros, unhas aparadas e sem esmalte, e não utilizavam adornos. Utilizavam luvas durante a manipulação e todos os utensílios e equipamentos em desuso eram protegidos com plástico filme de PVC (resinite) para evitar a contaminação dos mesmos. Germano e Germano (2003) descreveram em seu estudo que a maioria das pessoas envolvidas na manipulação de alimentos necessita de conhecimentos sobre medidas básicas de higiene a serem empregadas em produtos alimentícios, assim como desconhecem a possibilidade de serem portadores assintomáticos de microorganismos, contribuindo para a contaminação do alimento.

Esta lista de verificação buscou avaliar todo o setor, desde os funcionários até estrutura física do setor, tudo como descreve as Boas Práticas de Fabricação. Segundo Nascimento (2007) apud Seixas (2008) estas são compostas por um conjunto de princípios e regras para o correto manuseio de alimentos, que abrange desde a recepção das matérias-primas até o produto final, o seu principal objetivo é garantir a integridade do alimento e a saúde do consumidor. 
Thayse Wilma Nogueira de Oliveira \& Luciana Façanha Marques

\section{Conclusões}

Diante de todos os resultados obtidos, pode-se afirmar que as condições higiênicosanitárias na preparação dos Sushis e Sashimis do estabelecimento em estudo não são adequadas, sendo que foi indicada contaminação nos testes realizados. Nas análises de $S w a b$ os resultados comprovam esta afirmação, pois apenas uma das oito amostras analisadas não apresentou uma alta contagem de bactérias mesófilas. Indicando alto risco de contaminação do produto final através de equipamentos, utensílios e manipulador, demonstrando assim a falta de higienização dos mesmos.

Somente um dos produtos prontos para consumo avaliados se mostrou imprópria para o consumo, pois continha uma alta contaminação por Staphylococcus spp., bactérias presentes na pele e no trato respiratório, que chegam ao alimento através de mãos e antebraços não higienizados antes da manipulação.

A lista de verificação do setor indicou poucas não conformidades no setor, sendo no total 6 de 28 avaliadas, sendo que estas encontradas são pontos importantes no manual de Boas Práticas de Fabricação, indicando o não seguimento completo destas regras importantes para qualquer serviço de alimentação, principalmente na produção de um alimento de alto risco ao consumidor.

\section{Referências}

ABERC. Manual ABERC de práticas de elaboração e serviço de refeições para coletividades. São Paulo, p. 136, 2000.

ANVISA - RDC N¹2, 02 de Janeiro de 2001 da Agência de Vigilância Sanitária do Ministério da saúde. Regulamento técnico sobre os padrões microbiológicos para alimentos. Disponível em:< http://www.anvisa.gov.br/-

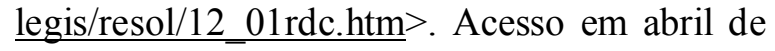
2011.
ANVISA. Legislação de Boas Práticas para Serviços de Alimentação. Resolução RDC n²16, de 15 de setembro de 2004. Disponível em:

http://elegis.anvisa.gov.br/leisref/public/showA ct.php?id=12546. Acesso em 05 de maio de 2011.

BRASIL. Ministério da Saúde. Secretaria de Vigilância Sanitária - Portaria 326, de 30 de julho de 1997. Aprova o Regulamento Técnico sobre "Condições HigiênicoSanitárias e de Boas Práticas de Fabricação para Estabelecimentos Produtores/Industrializadores de Alimentos. Diário Oficial da União; Poder Executivo, de 01 de agosto de 1997.

CHAYB, A. P. V. Segurança alimentar, globalização e modismos alimentares: o consumo de sushi e fast foods e sua interface com o desencadeamento de doenças crônicas. Fortaleza, Universidade Federal do Ceara, 2010. Dissertação, Centro de Ciências da Saúde da Universidade Federal do Ceará, Fortaleza, 2010.

CARDOSO, N. C. L. Avaliação da qualidade microbiológica de carne de peixe comercializada em supermercados da cidade de Goiânia, GO. Revista Higiene Alimentar, 17 (109): 81-87, 2003.

FILHO, L. G. M. de M. Enumeração e pesquisa de Vibrio spp. e coliformes totais e termotolerantes em sashimis de atum e vegetais comercializados na região metropolitana do Recife, Estado de Pernambuco. Acta Sci. Technol. Maringá, v. 29, n. 1, p. 85-90, 2007

FRANCO, B. D. G. LANDGRAF, M. Microbiologia dos alimentos. São Paulo: Atheneu; 2003.

GERMANO, P. M. L; GERMANO, M. I. S. Higiene Vigilância Sanitária de Alimentos. 2. ed. São Paulo: Varela, 2003. 655p.

HANASHIRO, A; Avaliação da comercialização de refeições orientais prontas - 
Thayse Wilma Nogueira de Oliveira \& Luciana Façanha Marques

Bentos - no bairro da liberdade, São Paulo. Higiene Alimentar, 1999; 13 (66): 19-31.

HAZELWOOD, D; McLEAN, A. C. Manual de higiene para manipuladores de alimentos. São Paulo: Livraria Varela, 1994.

LIMA, C. R.. Manual prático de controle de qualidade em supermercados. 1 ed. São Paulo: livraria Varela, 2001.

MARTINS, F. de O. Avaliação da qualidade higiênico-sanitária de preparações (sushi e sashimi) a base de pescado cru servidos em bufês na cidade de São Paulo. São Paulo: Universidade de São Paulo, 2006. Dissertação, Programa de Pós-graduação em Saúde Pública da Faculdade de São Paulo da Universidade de São Paulo, Campinas, 2006.

NASCIMENTO, G. A.; BARBOSA, J. S. BPF - Boas Práticas de Fabricação: uma revisão. Higiene Alimentar, São Paulo, v. 21, n. 148, p. 24-30, 2007.

PIRES, Ana Clarissa dos Santos; ARAÚJO, Emiliane Andrade; CAMILLOTO, Geany Peruch; RIBEIRO, Márcia Cristina Teixeira; SOARES, Nilda de Fátima Ferreira; ANDRADE, Nélio José de. Condições higiênicas de fatiadores de frios avaliadas por atp-bioluminescência e contagem microbiana: sugestão de higienização conforme RDC 275 da ANVISA. Alim. Nutr., Araraquara. v. 16, n. 2, p. 123-129, abr./jun. 2005.

SEIXAS, Fernanda R. F.; SEIXAS, Juliana R. F.; REIS, Janaína A.; HOFFMAM, Fernando L. Check-list para diagnóstico inicial das boas práticas de fabricação (BPF) em estabelecimentos produtores de alimentos da cidade de são josé do rio preto (SP). Revista Analytica, Fevereiro/Março 2008, No33.

SILVA, M. L. da. Pesquisa de Aeromonas spp. da qualidade sanitária de peixes comercializados na cidade de São Paulo.São Paulo: Universidade de São Paulo, 2007. Dissertação, Programa de Pós-graduação em
Saúde Pública da Faculdade de São Paulo da Universidade de São Paulo, São Paulo, 2007.

SIQUEIRA, R. S. de. Manual de microbiologia de alimentos. Brasília: SPIEMBRAPA; 1995.

VANZO, S.P. \& AZEVEDO, R.V.P. Detecção de S. aureus em manipuladores de alimentos: perfil de resistência a antibióticos e quimioterápicos. Higiene Alimentar, v. 17, n. 104/105, p. 144-122, jan.-fev. 2003.

WARD, Dr. Microbiological quality of fishery products. In: Martin AM. Fisheries processing, biotechnological application. London: Chaoman and Hall; 1994. P.1-17. 